\title{
Grammatical gender inhibition in bilinguals
}

\author{
Luis Morales*, Daniela Paolieri and Teresa Bajo
}

Department of Experimental Psychology and Behavioural Physiology, University of Granada, Granada, Spain

\section{Edited by:}

Judith F. Kroll, Penn State University, USA

\section{Reviewed by:}

Laurie Ann Stowe, University of Groningen, Netherlands

Wido La Heij, Leiden University, Netherlands

Jared Linck, University of Maryland

Center for Advanced Study of

Language, USA

\section{*Correspondence:}

Luis Morales, Department of Experimental Psychology and Behavioural Physiology, University of Granada, Campus de Cartuja s/n,

18071, Granada, Spain.

e-mail: luismorales@ugr.es
Inhibitory control processes have been recently considered to be involved in interference resolution in bilinguals at the phonological level. In this study we explored if interference resolution is also carried out by this inhibitory mechanism at the grammatical level. Thirty-two bilinguals (Italian-L1 and Spanish-L2) participated. All of them completed two tasks. In the first one they had to name pictures in L2. We manipulated gender congruency between the two languages and the number of presentations of the pictures ( 1 and 5 ). Results showed a gender congruency effect with slower naming latencies in the incongruent condition. In the second task, participants were presented with the pictures practiced during the first naming task, but now they were asked to produce the $L 1$ article. Results showed a grammatical gender congruency effect in $\mathrm{L} 1$ that increased for those words practiced five times in L2. Our conclusion is that an inhibitory mechanism was involved in the suppression of the native language during a picture naming task. Furthermore, this inhibitory process was also involved in suppressing grammatical gender when it was a source of competition between the languages.

Keywords: grammatical gender, inhibition, bilinguals

\section{INTRODUCTION}

One important question in bilingual language processing is how people who speak two or more languages are able to control their linguistic production. People immersed in a context of second language acquisition often make mistakes and access native language words even when the alternative language is needed (Kroll and Stewart, 1994; Colomè, 2001). Furthermore, sometimes they report forgetting some words in their native language, when it is infrequently practiced (Seliger and Vago, 1991; De Bot, 1999). One approach to understanding these detrimental effects has been to propose that they are produced by a process that is similar to that producing forgetting during memory retrieval. Levy et al. (2007) have shown that retrieving some information from memory can produce forgetting of associated competing information (Anderson et al., 1994). They have suggested that forgetting of first-language lexical representation when immersed in a second language context may be due to an attentional inhibitory mechanism that suppresses unwanted memories to facilitate retrieval of the relevant information (Levy et al., 2007). In general, any situation that requires memory retrieval in the presence of competition will entail inhibition of the competing information (Anderson et al., 1994, 2000; Anderson and Spellman, 1995; Anderson and McCulloch, 1999; Anderson and Green, 2001). An indirect consequence of this process is that the inhibited information will be less accessible and harder to retrieve at a later moment. Two important properties of inhibition as a memory selection mechanism is that (1) inhibition depends on the presence of competition (Anderson et al., 1994); and (2) it is specific to the dimension of the memory representation that is competing for selection, meaning that inhibitory effects should depend on the degree to which the memory trace tapped by the final test matches the memory trace that was competing during the encoding phase. For example, if competition is lexical in nature (i.e., words starting with the same beginning), inhibition will specifically act upon the lexical representation that will be less accessible in a later test. But, to capture lexical inhibition, a lexical test (i.e., lexical decision) would be needed (Tulving and Thomson, 1973; Morris et al., 1977; Bajo et al., 2006).

Hence, similar to what occurs in memory, first-language forgetting may arise, at least in part, from the suppression or inhibition of native language. For that to occur, interference and competition between the two languages of the bilingual are required (Kroll and Stewart, 1994). The aim of the experiments reported in this paper is to show that in similar vein grammatical gender can also be inhibited. In order to provide a context for this claim, we will first discuss the evidence regarding language co-activation and between-language competition at the lexical and grammatical level and next we will go back to the evidence regarding inhibitory control in language selection.

\section{LANGUAGE CO-ACTIVATION AND COMPETITION}

Numerous studies have provided evidence that linguistic properties of the non-intended language affect the production of the intended language at the semantic and the phonological levels (Hermans et al., 1998; Costa and Caramazza, 1999; Costa et al., 1999, 2000; Colomè, 2001; Dijkstra, 2005; Macizo and Bajo, 2006; but see Costa et al., 2006, for a critical discussion). For instance, in a series of picture-word tasks, Costa et al. (1999) reported lexical connections between the two systems of bilingual Catalan-Spanish speakers. They found interference effects when participants had to name pictures presented with semantically related words for both same- and different-language conditions, relative to when they were presented with semantically unrelated words. On the other hand, Colomè (2001) used a phoneme monitoring task on words self-elicited from pictures to demonstrate that the language that a bilingual is not using is nevertheless activated. When 
Spanish-Catalan bilinguals had to decide if a specific phoneme was present in the Catalan name of the picture, participants took longer to reject the phoneme when it was part of the Spanish word relative to a control condition.

Given the evidence of interaction between the semantic and phonological features of the lexical systems in bilinguals, we can also expect between-language competition at the level of grammatical gender. Grammatical gender has been proposed to be a property of the nouns that is stored at one representational level different from conceptual and phonological information (Caramazza and Miozzo, 1997; Levelt et al., 1999). However, how grammatical gender interacts during lexical selection in bilinguals is more controversial (Costa et al., 2003; Salamoura and Williams, 2007; Bordag and Pechmann, 2008; Lemhöfer et al., 2008; Paolieri et al., 2010a), probably due to the different characteristics of the gender systems in different languages. For instance, Costa et al. (2003) assume a complete autonomy of the gender systems of the two languages of the bilinguals. In a series of picture naming experiments manipulating grammatical gender congruency in different pairs of languages, the authors found similar naming times for same- and different-gender pictures. Costa et al. (2003) concluded that the grammatical gender of the words in the non-response language does not affect lexical processing in the response language. In contrast, Bordag and Pechmann (2007) and Lemhöfer et al. (2008) reported L1 and L2 interactions at the grammatical level of representation in Czech-German and German-Dutch bilinguals, respectively. Furthermore, they observed between-language gender interaction even when they controlled for the influence of phonological form (e.g., noun termination) in both production and comprehension tasks (Bordag and Pechmann, 2007); and even when using a lexical decision task where the cognate status of the words was manipulated (Lemhöfer et al., 2008).

Within the context of bilingualism, the effect of gender congruency has been also found in both bare noun production and noun phrase production with German-Dutch and Italian-Spanish speakers (Lemhöfer et al., 2008; Paolieri et al., 2010a) ${ }^{1}$. Paolieri et al. (2010a) observed robust gender congruency effects with Italian-Spanish bilinguals. In this study participants had to name pictures in L2 or to translate words from L1 to L2, producing either bare noun or noun phrases. In all conditions, participants showed shorter response latencies when the nouns of the two languages shared grammatical gender than when their grammatical gender was different. Thus, independently of the type of task (L2 picture naming or forward translation) and on the type of response (bare noun or noun phrase), their results speak in favor of grammatical gender interactions between the two languages of the bilinguals. These results contradict the notion that grammatical gender is

\footnotetext{
${ }^{1}$ The selection of grammatical gender in bare noun production is a controversial topic in monolingual language production. A reliable effect of grammatical gender congruency in bare noun production has been found in Italian and Spanish, two Romance languages with a similar morphological system. In contrast, with Italian and Spanish, the gender congruity effect has never been observed in Dutch (La Heij et al., 1998; Starreveld and La Heij, 2004), where no inflection has to be selected for the production of bare nouns. To explain the different pattern of results in Italian, Spanish, and Dutch, Cubelli et al., 2005; see also Paolieri et al., 2011) assumed that the gender congruency effect in the picture-word paradigm depends on the specific, formal, morphosyntactic properties of individual languages.
}

only selected when producing gender-marked utterances (Caramazza and Miozzo, 1997; Levelt et al., 1999), and support the idea that the selection of one lexical node involves obligatory access to syntactic features (Cubelli et al., 2005; Paolieri et al., 2010a,b). And more importantly, they suggest that the two lexical-grammatical representations of the words are activated in the bilinguals mind and compete whenever lexical selection is needed.

\section{INHIBITORY CONTROL IN LANGUAGE SELECTION}

Given that most studies point to a non-selective activation of languages during bilingual production, the question concerns how the system handles such unintended activation. For example, the model proposed by Costa and collaborators (Costa et al., 1999; Costa, 2005) assumes that although the lexical candidates in both languages are active simultaneously, the intention to speak only one of them restricts selection to the target language. In this way, co-activation does not lead to interference and competition during the planning of the utterance.

However, another possibility is that both lexical representations also compete for selection, and that such selection is managed by inhibitory processes acting on the lexicon. One version of inhibitory model (Inhibitory Control Model; Green, 1998) claims that inhibitory control is triggered whenever active lexical representations from the two languages compete for selection. This inhibitory mechanism is in charge of suppressing the non-target representations; as a consequence between-language interference is reduced and selection of the appropriate entries is facilitated. The role of inhibitory processes on selection is not restricted to the bilingual field, but it is shared with other cognitive areas such as visual attention, memory and language comprehension and production. For example, popular explanations of the inhibition of return effect (e.g., Tipper et al., 2003) have suggested that already-sampled spatial locations are inhibited to facilitate visual search. Similarly, some memory theories assume that inhibition of competing representation facilitate retrieval of target memories (Anderson et al., 1994), and many theories of language production assume that lexical selection is achieved by means of inhibitory connections at the level of lexical representations (e.g., Berg and Schade, 1992; Cutting and Ferreira, 1999). Hence, research in different cognitive domains has suggested that both lexical and perceptual representations can be inhibited.

Most of the evidence regarding inhibitory language control comes from results of the language switching tasks (Meuter and Allport, 1999; but see Abutalebi and Green, 2008; for a review). In these studies participants are required to name digits or pictures in $\mathrm{L} 1$ or L2 in an unpredictable manner. Hence, there are trials in which the response language is the same as that in the preceding trial (non-switch trials) and trials in which the response language differs from the preceding trial (switch trials). When bilinguals perform this task they are slower in switching trials relative to non-switch trials (switching cost), but the most interesting pattern is that switching from L2 to L1 produces a larger cost than switching from L1 to L2. This asymmetrical cost has been interpreted as evidence of inhibition by assuming that naming in L2 requires inhibition of the more dominant $\mathrm{L} 1$, so that when bilinguals switch back into the L1 naming, additional time would be required to overcome the strong inhibition of L1 representations. 
Similarly, Linck et al. (2009) provided support for the inhibitory account in a study in which they compared L2 learners immersed in a L2 context with L2 learners without immersion experience. In a very simple task, they showed that relative to classroom learners, the immersed learners produced significantly more examples in L2, but more interestingly, they produced significantly fewer examples in their L1, indicating that L2 immersion increases the amount of inhibition on L1 so that L1 become less available for the immersed bilinguals. Note that inhibition in the language switching and verbal fluency tasks are global in nature and directed to the non-appropriate language. In this sense, these tasks do not tap into specific memory representations since the lexical and conceptual units change from one trial to next and therefore is the language what it needs to be inhibited.

Evidence for representation specific inhibition comes from several recent lines of research. For example, Macizo et al. (2010) and Martín et al. (2010) asked Spanish-English bilinguals to perform a relatedness judgment task including interlexical homographs (e.g., "pie," meaning "foot" in Spanish). Pairs of English words were presented and the participants had to decide whether or not they were related. Results indicated that participants were slower to respond to homographs presented along with words related to the irrelevant Spanish meaning of the homograph relative to control words (e.g., "pie-toe" vs. "log-toe"). Moreover, after responding to homographs, the participants responded more slowly when the following trial required activation of the irrelevant homograph meaning (e.g., "foot-hand" preceded by "pie-toe"). These results suggest that bilinguals activated both of their languages (homograph interference) and that they inhibited the irrelevant homograph meaning in order to overcome interference and perform the task.

Similarly, Levy et al. (2007) have also demonstrated that inhibition is responsible for the suppression of native language at the phonological level. In their study, native English speakers had to name pictures in Spanish-L2 for 1, 5, or 10 times (e.g., culebra; snake). Afterward, the accessibility to the same words in the native language was measured using an independent probe (Anderson and Spellman, 1995) rhyme test (e.g., break-s

Results showed that words named in Spanish (L2) 5 or 10 times led to decreased recall of the corresponding English (L1) names than those named in L1 or named in L2 only once. Moreover, in Experiment 2 they were able to isolate the specific inhibitory effect to phonology since presenting semantic cues (e.g., venom-s did not produce the forgetting effect of naming repeatedly pictures in L2. Thus, repeatedly naming L2-words inhibited the phonology of their English (L1) names, but facilitated concept accessibility. The authors conclude that phonological first-language attrition arises from inhibition of the phonological native language representations during second language use. This experiment illustrates the importance of inhibitory mechanism in overcoming interference during second language acquisition.

Hence, although there is much evidence showing that the two language systems of the bilingual interact at the semantic, phonological, and grammatical levels (Costa and Caramazza, 1999; Costa et al., 2000; Colomè, 2001; Paolieri et al., 2010a), and that inhibitory mechanisms are triggered to reduce the interference due to co-activation at the semantic (Macizo et al., 2010; Martín et al., 2010) and phonological level (Levy et al., 2007; but see Finkbeiner et al., 2006, for a critical discussion), there is no evidence showing that inhibitory processes can also act at the lexical/grammatical (gender) level of representation.

The aim of this study is to confirm that the two lexical systems of the bilingual are activated and interact at the grammatical gender level, and more interestingly, to investigate whether inhibitory mechanisms are responsible for resolving between-language competition at this representational level. Similarly to Levy's study (Levy et al., 2007), we asked Italian native speakers to name pictures in Spanish-L2 by producing bare nouns. In this first picture naming phase, we manipulated the gender congruency of the nouns between the two languages (grammatical gender congruent vs. grammatical gender incongruent) and the number of presentations of each picture (one or five times), in order to create more or less L1 inhibition. Note that picture naming involves the activation of the grammatical properties of the language (Cubelli et al., 2005; Paolieri et al., 2010a,b), as long as these grammatical properties of the two languages are activated and are incongruent (Paolieri et al., 2010a), they will compete for selection and the inappropriate grammatical feature would be inhibited. Hence, words with incongruent gender in the two languages would produce competition that in turn would trigger inhibition. In addition, the higher the number of naming trials in L2, the greater the inhibition that would act upon the particular L1 incongruent grammatical property.

In the second phase, participants had to complete an article production task in Italian-L1 for the same pictures practiced in L2 during the first task. This task was selected because it specifically captures gender access since participants are asked to produce only the definite article. We expected that trials containing incongruent gender stimulus would show slower response times when producing the article in L1; and more importantly, that this difference would be larger for words practiced more times in the previous L2 naming task. For this later task, new pictures (never presented during the naming phase of the experiment) were added as a baseline to observe the effect of previous naming (see Levy et al., 2007, for a similar procedure). Given that participants had to produce the definite article in their native language, we did not expect gender effects for these new items.

\section{MATERIALS AND METHODS PARTICIPANTS}

Thirty-two Italian-Spanish bilinguals voluntarily participated in the experiment. L2 proficiency was assessed at the end of the session through a subjective questionnaire (see Table A1 in Appendix for a description of the sample of participants). They all had normal or corrected-to-normal vision.

\section{DESIGN AND MATERIALS}

The experiment consisted of two main phases: (1) Picture naming task in L2 (Spanish) by producing bare nouns, and (2) Retrieval of $\mathrm{L} 1$ article corresponding to the presented pictures. This design was created in order to produce the inhibition of Italian-L1 gender by naming gender congruent and incongruent items in Spanish-L2 during the first part of the experiment, and then measure access to the specific representations of these lexical entries during the Italian-L1 task (see Levy et al., 2007, for a similar procedure). 
Grammatical gender (Congruent vs. Incongruent) and Number of presentations of each picture (1 vs. 5) were manipulated within subjects during the Spanish (L2) naming task. Seventytwo pictures were chosen from the sets of Lotto et al. (2001), half with the same gender in Italian and Spanish (e.g., Sciarpa $a_{F E M}$ and $B$ fand $a_{F E M}$, in Italian and Spanish respectively -scarf-) and half with different gender (e.g., Letto MAS $_{\text {and }}$ Cama $_{F E M}$, in Italian and Spanish respectively-bed-). At the same time, half of the words were masculine and half were feminine in gender. This set of stimulus consisted of 48 experimental pictures to be used both in the first and second task, and 24 additional control items to be included as baseline for the second task (a complete list of the stimulus materials is provided in Table A2 in Appendix). Cognate words were not included as experimental material. Gender Congruent and Incongruent words did not differ (all $t s<1$ ) for frequency (Alameda and Cuetos, 1995 for Spanish, and Bertinetto et al., 2005 for Italian), number of letters, number of syllables, and phonological/orthographic overlap. The last one was calculated computing the percentage of number of letters shared by the words in the two languages.

For the picture naming task in L2 (task 1), half of the pictures were presented once and half five times. Two different pseudorandom lists including 48 experimental items were created. Lists were constrained as follows: (1) No more than three congruent or incongruent stimuli could appear consecutively; (2) the lag between repetitions of a particular picture had to be of at least three trials; (3) no semantic or phonological relationship could exist between pictures in consecutive trials. Finally, each list included a total of 144 trials. Repetitions of each picture and list were counterbalanced across participants.

Regarding the article retrieval task in L1 (task 2), one randomized list was created and divided in two blocks counterbalanced across participants. The list consisted of a total of 72 trials ( 48 experimental pictures named in L2 during the previous task plus 24 new control pictures).

\section{PROCEDURE}

Participants were tested individually. The experimenter was seated behind the participant to record errors and responses. The stimuli were presented using E-Prime experimental software, 1.1 version (Schneider et al., 2002). The whole experiment lasted about $40 \mathrm{~min}$. Before starting, participants completed a familiarization phase with the complete set of pictures. A trial in the familiarization phase consisted of the presentation of each picture with its translation in both languages (e.g., "Il letto - La cama," for the picture of a bed). The participants had to indicate to the experimenter if they knew the words in Spanish (L2). Then, the experimental tasks were administered in the following order: (1) Picture naming task in L2 and (2) article naming task in L1.

\section{Task 1: picture naming task in L2}

The objective of this task was to produce inhibition of the nouns in Italian-L1. Participants had to name pictures in Spanish-L2, and they were instructed to name them as quickly and accurately as possible using the bare noun (i.e., without using the define article " $e l$ " or "la" in Spanish). A trial consisted of the following events: A fixation point $(+)$ presented at the center on screen for $750 \mathrm{~ms}$; presentation of the picture until the participants' response or for a maximum of $4000 \mathrm{~ms}$; and a blank interval for $750 \mathrm{~ms}$ before the next trial. A practice block of 12 trials was administrated before starting the task. Naming latencies were measured from the onset of the stimuli until the beginning of the response. Naming errors and equipment failures were registered.

\section{Task 2: article production task in L1}

The objective of this task was to measure the speed of access to the grammatical gender information of those nouns practiced during the previous task in L2. For that, the participants had to retrieve and name the definite article corresponding to the presented pictures (the same practiced in L2 during the previous task plus the new control items). Each trial consisted of the following sequence of events: A fixation point $(+)$ for $750 \mathrm{~ms}$; the presentation of the picture that remained on the screen until response or for a maximum of $4000 \mathrm{~ms}$; and a blank interval for $750 \mathrm{~ms}$.

Finally, an L2 subjective questionnaire was administered.

\section{RESULTS}

\section{TASK 1: PICTURE NAMING IN L2}

Several types of responses were excluded: (1) Naming latencies below $300 \mathrm{~ms}$ and exceeding $2500 \mathrm{~ms}$, (2) naming errors and verbal dysfluencies, (3) Spanish words unknown by the participant. Overall, $24.11 \%$ of the trials were excluded from the analyses [70\% of that percentage was due to non-responses, and these trials were not included in the analyses of the second task (see below)]. An ANOVA introducing Grammatical Gender (Congruent vs. Incongruent) and Number of Presentations for each picture (1 vs. 5) revealed a main effect of Grammatical Gender $[F(1,31)=4.367$, $\mathrm{MSE}=2.954, p=0.004]$, with congruent items $20 \mathrm{~ms}$ faster than incongruent ones $[884 \mathrm{~ms}(\mathrm{SD}=176)$ and $904 \mathrm{~ms}(\mathrm{SD}=177)$, respectively]. The main effect of Number of Presentations was also significant $[F(1,31)=183.474, \mathrm{MSE}=11.525, p=0.0001]$, revealing faster naming latencies with pictures practiced more times $[1022 \mathrm{~ms}(\mathrm{SD}=131)$ and $756 \mathrm{~ms}(\mathrm{SD}=110)$, for pictures practiced once or five times, respectively]. Finally, the interaction between the variables was not significant $[F(1,31)=0.855$, $\mathrm{MSE}=4.565, p=0.362]$.

\section{TASK 2: ARTICLE PRODUCTION TASK IN L1}

Naming errors (8.37\% of the trials), verbal dysfluencies, response times below $300 \mathrm{~ms}$ and exceeding $2500 \mathrm{~ms}$, and naming latencies for those pictures that were never successfully named during the previous task in L2 were eliminated from the analysis (overall, $31.34 \%$ of the trials). Naming errors included cases where the participants produced the wrong name of the picture as well as the wrong article (unfortunately our coding system did not permit to separate the two types of naming errors). An analysis of these combined errors comparing the Congruent and Incongruent conditions showed that incongruent nouns produced significantly more errors than congruent ones (109 and 64, respectively) $[F(1,31)=12.1304, \mathrm{MSE}=2.6084, p=0.001]$. Regarding the latencies for the article production, an ANOVA including Grammatical Gender (Congruent vs. Incongruent) $\times$ Number of Presentations (0,1, and 5) showed a main effect of Grammatical Gender $[F(1,31)=19.684$, MSE $=19.429, p=0.0001]$, Number 
of Presentations $[F(2,62)=10.021, \mathrm{MSE}=14.039, p=0.0001]$, and the interaction of Gender $\times$ Number of Presentations $[F(2$, $62)=11.554, \mathrm{MSE}=11.163, p=0.0001]$.

In order to understand this interaction, we compared, first, congruency effects for each level of repetition. Planned comparisons yielded significant differences between congruent and incongruent items practiced once in L2, with slower RT in the incongruent condition $[1089 \mathrm{~ms}(\mathrm{SD}=203)$ and $1200 \mathrm{~ms}(\mathrm{SD}=195) ; F$ $(1,31)=17.224, p=0.0002]$. This difference was also significant when the pictures were practiced five times [1091 ms $(\mathrm{SD}=196)$ for congruent and $1257 \mathrm{~ms}(\mathrm{SD}=213)$ for incongruent; $F(1$, $31)=27.074, p=0.0001]$, but not when the pictures were practiced zero times $[1241 \mathrm{~ms}(\mathrm{SD}=220)$ for congruent and $1231 \mathrm{~ms}$ $(\mathrm{SD}=193)$ for incongruent; $F(1,31)=0.100, p=0.752]$. Note that non-repeated pictures were never named in L2, and therefore they were never subject to interference. Because article production for these new pictures was performed in L1, it is not surprising that congruency effect were not present. However, when the pictures were named in L2 and they were incongruent, the more times the pictures were named in L2, the harder to find the appropriate article in L1. That is, the gender congruency effect became larger with repetitions because incongruent articles were harder to retrieve.

When we compared 1 vs. 5 L2 naming for congruent and incongruent items, repetition effects were only present for the incongruent condition ${ }^{2}$. The results of these comparisons indicated that for incongruent nouns significant differences between pictures practiced one and five times in L2 were obtained, with slower RT for the pictures practiced five times [1200 $\mathrm{ms}(\mathrm{SD}=195)$ and $1257 \mathrm{~ms}$ $(\mathrm{SD}=213) ; F(1,31)=4.896, p=0.03]$. In contrast, this difference was not significant for congruent items [ $1089 \mathrm{~ms}(\mathrm{SD}=203)$ for one repetition and $1091 \mathrm{~ms}(\mathrm{SD}=196)$ for five repetitions; $F(1$, $31)=0.006, p=0.93]$. This pattern indicates that the congruency effect was driven by an increased interference in the incongruent condition with more repetitions, and not by facilitation in the congruent condition across repetitions.

\section{DISCUSSION}

The aim of this study was to demonstrate that not only the two gender systems of a bilingual are functionally connected, but also that this co-activation can cause competition processes that are resolved by inhibitory mechanisms at the grammatical level of representation. In the first phase of the experiment, we found

\footnotetext{
${ }^{2}$ It could be argued that the proper comparison to claim inhibitory effects is the comparison between zero and five repetitions. In fact, RIF effects in standard memory procedures with categorical materials come from comparing practiced items from practiced categories to items belonging to unpracticed categories. However, we think that in the present procedure the proper comparison involves one to five repetitions. Standard RIF with categorical material involves the presentation of common familiar concepts, whereas the L2 picture naming task in the present experiment (see also Levy et al., 2007) involves the presentation of new unfamiliar pictures (depicting common objects). Hence, the first naming trial would increase the familiarity with the picture and produce facilitation (see Johson and Anderson, 2004; and Levy et al., 2007, for further discussion and similar results in other inhibitory paradigms). Although not significant $(p>0.05)$, Figure 1 shows that RT to items named for the first time is faster than the RT to new items, these differences in perceptual familiarity may obscure inhibitory effects when comparing $0-5$ repetitions in incongruent trials $(p>0.05)$. However, the inhibitory effects clearly emerge when comparison involve already familiar items ( 1 vs. 5 presentations).
}

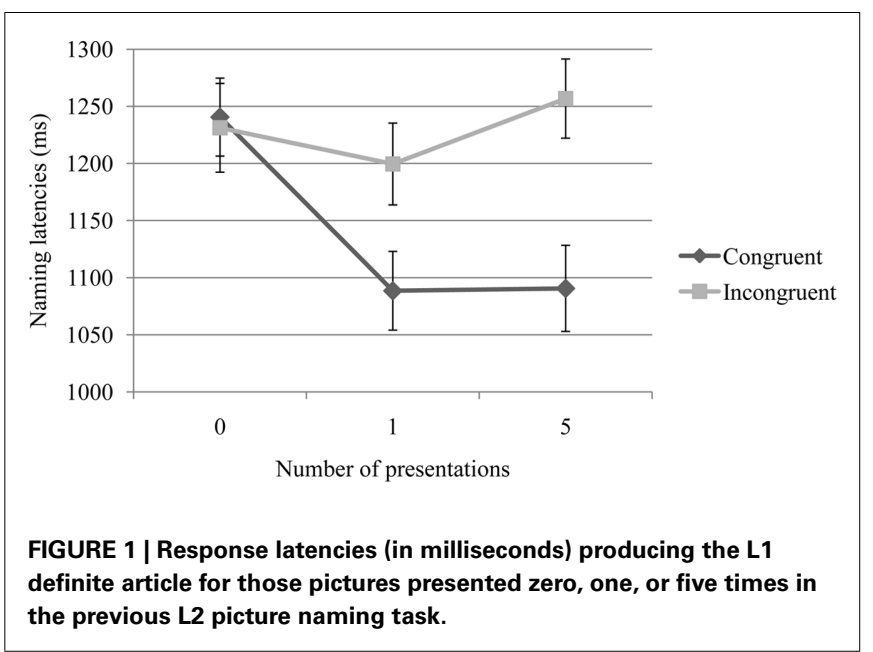

that participants took more time naming pictures with incongruent Italian-Spanish gender. Furthermore, this effect was observed through a bare noun picture naming task in which explicit access to the grammatical gender information of each word is not mandatory. This result supports the notion that grammatical gender selection is not constrained to noun phrase production tasks, in which explicit access to the gender representation is required (i.e., when participants are asked to name pictures using the gendermarked definite article; Cubelli et al., 2005; Paolieri et al., 2010a,b), and that grammatical gender is a lexical property that is automatically activated and interacts across the bilinguals lexical systems (Bordag and Pechmann, 2007; Lemhöfer et al., 2008; Paolieri et al., 2010a). Although we do not have a monolinguals control condition in the experiment to show that the effect is really due to between-language activation in bilinguals and to possible differences between gender congruent and incongruent words, Paolieri et al. (2010b) tested Italian monolingual participants with similar materials and showed that this effect was not present in monolinguals. In summary, results from task 1 suggest that grammatical gender is an intrinsic part of the lexical representation, and it is always available when a noun is retrieved (Paolieri et al., 2010a,b). Therefore, gender effects should be observed in all tasks requiring lexical access, whether producing a noun phrase with explicit gender markers or the bare noun along.

In our study, between-language gender incongruency introduced competition so that when there was no agreement between Italian-Spanish gender for the corresponding object, naming latencies were slower than when there was agreement between them. This between-language competition at the grammatical level seems to have triggered inhibitory processes. Then, the interference created by gender incongruency was resolved by inhibiting grammatical gender representation of the Italian-L1 words in order to facilitate the correct naming of each picture in Spanish-L2. Because of this inhibition, later retrieval of L1 grammatical information (retrieving the appropriate article) of incongruent words took longer relative to the retrieval of the appropriate article for gender congruent pictures.

According to the IC model (Green, 1998); bilinguals trigger inhibitory control mechanisms to select the desired 
representations when they experience between-language competition. In this study we show that during an L2 naming task both L1 and L2 lexical representations are activated and compete, in particular this competition is evident when the grammatical gender information in the two languages is incongruent. The results of the picture naming task demonstrate that the participants took more time naming the pictures when the grammatical gender of the corresponding names was incongruent than when it was congruent. This congruency effect demonstrates that $\mathrm{L} 1$ was activated even when only L2 was needed for naming and that this activation included grammatical features.

More importantly, results of the second task involving retrieval of the article in L1 indicate that the grammatical competition during L2 naming was resolved by specifically inhibiting the competing grammatical gender in L1. Note that in the article naming task access to the gender information was needed, and therefore it is a task that specifically taps gender processing, in order to measure the access of gender representation properly (see Bajo et al., 2006, for the importance of task specificity to test inhibition). Although we found a significant gender congruency effect between objects practiced once and five times, the fact that this effect in L1 is larger as the number of repetitions in L2 increases clearly show that this gender congruency effect is the result of the previous naming in L2. In addition, the absence of such effect with pictures never presented for L2 naming also signals that the slower response times with repetition are due to the mechanism involved in reducing gender interference during picture naming. Nevertheless, direct evidence in favor of an inhibitory account is provided when we focus on the effect of repetition on incongruent pictures and the increment in L1 article retrieval for pictures named five times in L2. The fact that this effect was absent for congruent objects tell us that the impairment is caused for the competition arisen for the incongruent between-language gender for the nouns, and not for facilitatory effects in the congruent condition.

However, it could be argued that this data are open to alternative explanations. First, it could be argued that the congruency effect is not due to the co-activation of grammatical features that compete for selection, but to the effect of determiners similarity. This might be the case because of the particular form of the determiners used in Spanish and Italian. Thus, in Spanish they are "el" for masculine and "la" for feminine, whereas in Italian there are "il"/"lo" for masculine and "la" for feminine. So, the incongruency effect could be interpreted as due to the similarity in word form of the Spanish and Italian feminine determiners. To rule out this alternative explanation we performed additional analyses introducing gender as a variable. If the gender effect was due to form similarity we should find that in the L2 naming task the masculine condition should produce longer effects than the feminine condition. The results of the ANOVA on the L2 naming times with Gender, Congruency, and Repetition as independent variables showed a main effect of Congruency [ $F$ $(1,31)=5.3811, p<0.05]$, and Repetition $[F(1,31)=173.934$, $p<0.05]$. However, Gender (feminine vs. masculine) was not significant and did not interact with any of the other variables (all $p s>0.05)$. This suggests that the congruency effect was not due to form similarity, but to gender incongruency. In addition, the ANOVA performed in the article naming task of the second phase showed that the critical Gender $\times$ Congruency $\times$ Repetition interaction was not significant $[F(2,56)=0.276, p>0.05]$. Indicating that Congruency $\times$ Repetition (the inhibitory index) was similar for both feminine and masculine.

Similarly, it could be argued that the effect of repetition in incongruent trials might be due to associative interference. Within the memory field, some have argued that the forgetting induced by retrieval of information is due to the strengthening of the practiced items with the contextual cue, so that when that cue is later presented for recall, the strengthen representation is activated first and block the retrieval of the non-practiced items (Raaijmakers and Shiffrin, 1981). In this context, this associative account would suggest that practice in L2 naming would strengthen the relation between the presented pictures and the L2 name, so that later, when participants saw the pictures again the strengthen L2 representation would come to mind and block the retrieval of the L1 representation. In the memory literature, this interpretation has been ruled out by showing that retrieval induced forgetting is also produce when the task used to capture forgetting of the unpracticed items does not test the strengthened relation. This is done by presenting either novel cues (Anderson and Spellman, 1995; Bajo et al., 2006) or item specific tests (Román et al., 2009). Although our procedure is not exactly cue independent, in our experiment the particular tasks used during the first and second phase were selected so that associative interference was not present. Thus, in the first phase a bare noun naming task was used to avoid the presentation of the L2 determiner, whereas in the second phase we asked participants to only name the L1 determiner corresponding to the object in the picture. Hence, the picture and the L2 determiner were never presented together during the first phase to produce strengthening of the picture-determiner representation. Hence, the relation between the picture and the L2 determiner was never strengthened and there are no reasons to think that the determiner in L2 was blocking retrieval of the L1 determiner.

Hence, the results speak in favor of the importance of inhibitory control mechanisms in resolving between-language competition in bilinguals at the grammatical gender level. Levy et al. (2007) observed co-activation at the phonological level and were able to show that phonological competition was resolved by means of inhibition of phonological representations. In our experiment, we were able to find a similar pattern of inhibition at the grammatical gender level. Together, both studies highlight the importance of executive control mechanisms for controlling language production in bilinguals.

In conclusion, grammatical gender information is a lexical representation that is automatically activated and can cause competition between-languages with similar gender systems. This interference seems to be solved by inhibitory mechanisms that suppress momentarily the grammatical gender representation of specific lexical entries. Although more research is needed to isolate the specific inhibition of competitive traces, the fact that competition processes are required for inhibition to occur seems to be clear. 


\section{ACKNOWLEDGMENTS}

This research was supported by doctoral research grant from the Andalusian Government (P08-HUM-03600) to Luis Morales; grants EDU2008-01111 and CSD2008-00048 from the Spanish

\section{REFERENCES}

Abutalebi, J., and Green, D. W. (2008). Control mechanisms in bilingual language production: neural evidence from language switching studies. Lang. Cogn. Process. 23, 557-582.

Alameda, J. R., and Cuetos, F. (1995). Diccionario de frecuencias de las unidades lingüisticas del castellano. Oviedo: Servicio de Publicaciones de la Universidad de Oviedo.

Anderson, M. C., Bjork, E. L., and Bjork, R. A. (2000). Retrieval-induced forgetting: evidence for a recall-specific mechanism. Psychon. Bull. Rev. 7, 522-530.

Anderson, M. C., Bjork, R. A., and Bjork, E. L. (1994). Remembering can cause forgetting: retrieval dynamics in long-term memory. J. Exp. Psychol. Learn. Mem. Cogn. 20, 1063-1087.

Anderson, M. C., and Green, C. (2001). Suppressing unwanted memories by executive control. Nature 410, 131-134.

Anderson, M. C., and McCulloch, K. C. (1999). Integration as a general boundary condition on retrievalinduced forgetting. J. Exp. Psychol. Learn. Mem. Cogn. 25, 608-629.

Anderson, M. C., and Spellman, B. A. (1995). On the status of inhibitory mechanisms in cognition: memory retrieval as a model. Psychol. Rev. 102, 68-100.

Bajo, T., Gómez-Ariza, C. J., Fernández, A., and Marful, A. (2006). Retrievalinduced forgetting in perceptually driven memory tests. J. Exp. Psychol. Learn. Mem. Cogn. 32, 1185-1194.

Berg, T., and Schade, U. (1992). The role of inhibition in a spreading activation model of language production. I. The psycholinguistic perspective. J. Psychol. Res. 21, 405-434.

Bertinetto, P. M., Burani, C., Laudanna, A., Marconi, C., Ratti, D., Rolando, C., and Thornton, A. M. (2005). CoLFIS (Corpus e Lessico di Frequenza dell' Italiano Scritto) [CoLFIS (Corpus and Frequency Lexicon of Writteen Italian]. Available at: http://www.istc.cnr.it/material/database [accessed July 6, 2006].

Bordag, D., and Pechmann, T. (2007). Factors influencing L2 gender processing. Biling. (Camb. Engl.) 10, 299-314.
Bordag, D., and Pechmann, T. (2008). Grammatical gender in translation. Second Lang. Res. 24, 139-166.

Caramazza, A., and Miozzo, M. (1997). The relation between syntactic and phonological knowledge in lexical access: evidence from the "tip-ofthe-tongue" phenomenon. Cognition 64, 309-343.

Colomè, A. (2001). Lexical activation in bilinguals' speech production: language-specific or languageindependent? J. Mem. Lang. 45, 721-736.

Costa, A. (2005). "Lexical access in bilingual production," in Handbook of Bilingualism: Psycholinguistic Approaches, eds J. F. Kroll and A. M. B. De Groot (New York: Oxford University Press), 308-325. lexical selection in bilingual speech production language-specific? Further evidence from SpanishEnglish and English-Spanish bilinguals. Biling. (Camb. Engl.) 2, 231-244.

Costa, A., Caramazza, A., and SebástianGallés, N. (2000). The cognate facilitation effect: implications for models of lexical access. J. Exp. Psychol. Learn. Mem. Cogn. 26, 1283-1296.

Costa, A., Kovacic, D., Franck, J., and Caramazza, A. (2003). On the autonomy of the grammatical gender systems of the two languages of a bilingual. Biling. (Camb. Engl.) 6, 181-200.

Costa, A., La Heij, W., and Navarrete, E. (2006). The dynamics of bilingual lexical access. Biling. (Camb. Engl.) 9, 137-151.

Costa, A., Miozzo, M., and Caramazza, guals: do words in the bilingual's two lexicons compete for selection? J. Mem. Lang. 41, 365-397.

Cubelli, R., Lotto, L., Paolieri, D., Girelli, M., and Job, R. (2005). Grammatical gender is selected in bare noun production: evidence from the pictureword interference paradigm. J. Mem. Lang. 53, 42-59.

Cutting, J. C., and Ferreira, V. S. (1999). Semantic and phonological information flow in the production lexicon. J. Exp. Psychol. Learn. Mem. Cogn. 25, 318-344.

De Bot, K. (1999). "The psycholinguistics of language loss," in Studies on Language Acquisition, eds G. Extra
Costa, A., and Caramazza, A. (1999). Is A. (1999). Lexical selection in bilin-

Ministry of Education; and grants P07-HUM-02510 and P08HUM-03600 from the Andalusian Government. We would like to thank Laure Ann Stowe, Wido la Heij, and Jared Linck for their helpful comments and suggestions.

and L. Verhoeven (Berlin: Walter de Gruyter), 345-361.

Dijkstra, T. (2005). "Bilingual word recognition and lexical access," in Handbook of Bilingualism: Psycholinguistic Approaches, eds J. F. Kroll and A. M. B. De Groot (New York: Oxford University Press), 179-201.

Finkbeiner, M., Almeida, J., Janssen, N. and Caramazza, A. (2006). Lexical selection in bilingual speech production does not involve language suppression. J. Exp. Psychol. Learn. Mem. Cogn. 32, 1075-1089.

Green, D. W. (1998). Mental control of the bilingual lexico-semantic system. Biling. (Camb. Engl.) 1, 67-81.

Hermans, D., Bongaerts, T., de Bot, K., and Schreuder, R. (1998). Producing words in a foreign language: can speakers prevent interference from their first language. Biling. (Camb. Engl.) 1, 213-230.

Johson, S. K., and Anderson, M. C. (2004). The role of inhibitory control in forgetting semantic knowledge. Psychol. Sci. 15, 448-453.

Kroll, J. F., and Stewart, E. (1994). Category interference in translation and picture naming: evidence from asymmetric connections between bilingual memory representations. $J$. Mem. Lang. 33, 149-174.

La Heij, W., Mark, P., Sander, J., and Willeboorsde, E. (1998). The gendercongruency effect in picture-word tasks. Psychol. Res. 61, 209-219.

Lemhöfer, K., Spalek, K., and Schriefers, H. (2008). Cross-language effects of grammatical gender in bilingual word recognition and production. $J$. Mem. Lang. 59, 312-330.

Levelt, W. J. M., Roelofs, A., and Meyer, A. S. (1999). A theory of lexical access in speech production. Behav. Brain Sci. 22, 1-75.

Levy, B. J., McVeigh, N. D., Marful, A., and Anderson, M. C. (2007). Inhibiting your native language: the role of retrieval-induced forgetting during second-language acquisition. Psychol. Sci. 18, 29-34.

Linck, J. A., Kroll, J. F., and Sunderman, G. (2009). Losing access to the native language while immersed in a second language: evidence for the role of inhibition in secondlanguage learning. Psychol. Sci. 20, 1507-1515.

Lotto, L., Dell'Acqua, R., and Job, R. (2001). Le figure PD/DPSS. Misure di accordosulnome, tipicità, familiarità, età di acquisizione e tempi di denominazione per 266 figure [PD/DPSS pictures: name agreement, typicality, familiarity, age of acquisition norms and naming times of 266 pictures]. GiornaleItaliano di Psicologia 28, 231-245.

Macizo, P., and Bajo, M. T. (2006). Reading for understanding and reading for translation: are they equal? Cognition 99, 1-34.

Macizo, P., Bajo, T., and Martín, M. C. (2010). Inhibitory processes in bilingual language comprehension: evidence from Spanish-English interlexical homographs. J. Mem. Lang. 63, 232-244.

Martín, M. C., Macizo, P., and Bajo, T. (2010). Time course of inhibitory processes in bilingual language processing. Br. J. Psychol. 101, 679-693.

Meuter, R. F. I., and Allport, A. (1999). Bilingual language switching in naming: asymmetrical costs of language selection. J. Mem. Lang. 40, 25-40.

Morris, C. D., Bransford, J. D., and Franks, J. J. (1977). Levels of processing versus transfer appropriate processing. J. Verbal Learn. Verbal Behav. 16, 519-533.

Paolieri, D., Cubelli, R., Macizo, P., Bajo, M. T., Lotto, L., and Job, R. (2010a). Grammatical gender processing in Italian and Spanish bilinguals. Q. J. Exp. Psychol. 63, 1631-1645.

Paolieri, D., Lotto, L., Morales, L., Bajo, T., Cubelli, R., and Job, R. (2010b) Grammatical gender processing in romance languages: evidence from bare noun production in Italian and Spanish. Eur. J. Cogn. Psychol. 22, 335-347.

Paolieri, D., Lotto, L., Leoncini, D. Cubelli, R., and Job, R. (2011). Differential effects of grammatical gender and gender inflection in the picture-word interference paradigm. Br. J. Psychol. 102, 19-36.

Raaijmakers, J. G. W., and Shiffrin, R. M. (1981). Search of associative memory. Psychol. Rev. 88, 93-134.

Román, P. E., Soriano, M. F., GómezAriza, C. J., and Bajo, M. T. (2009). Retrieval-induced forgetting and executive control. Psychol. Sci. 20, 1053-1058.

Salamoura, A., and Williams, J. N. (2007). The representation of 
grammatical gender in the bilingual lexicon: evidence from Greek and German. Biling. (Camb. Engl.) 10, 257-275.

Schneider, W., Eschman, A., and Zuccolotto, A. (2002). E-Prime User's Guide (Version 1.1). Pittsburgh, PA: Psychology Software Tools.

Seliger, H. W., and Vago, R. M. (eds). (1991). First Language Attrition. Cambridge: Cambridge University Press.
Starreveld, P. A., and La Heij, W. (2004). Phonological facilitation of grammatical gender retrieval. Lang. Cogn. Process. 19, 677-711.

Tipper, S. P., Grison, S., and Kessler, K. (2003). Long-term inhibition of return of attention. Psychol. Sci. 14, 19-25.

Tulving, E., and Thomson, D. M. (1973). Encoding specificity and retrieval processes in episodic memory. Psychol. Rev. 80, 352-373.
Conflict of Interest Statement: The authors declare that the research was conducted in the absence of any commercial or financial relationships that could be construed as a potential conflict of interest.

Received: 04 April 2011; paper pending published: 28 May 2011; accepted: 09 October 2011; published online: 25 October 2011.

Citation: Morales L, Paolieri D and Bajo $T$ (2011) Grammatical gender inhibition in bilinguals. Front. Psychology 2:284. doi: 10.3389/fpsyg.2011.00284

This article was submitted to Frontiers in Cognition, a specialty of Frontiers in Psychology.

Copyright (C) 2011 Morales, Paolieri and Bajo. This is an open-access article subject to a non-exclusive license between the authors and Frontiers Media SA, which permits use, distribution and reproduction in other forums, provided the original authors and source are credited and other Frontiers conditions are complied with. 


\section{APPENDIX}

Table A1 | Language history and self-evaluated proficiency scores of the Italian-Spanish bilinguals.

\begin{tabular}{ll}
\hline Age (years) & $24.66(4.83)$ \\
LANGUAGE HISTORY & \\
Use of L2 (years) & $2.88(4.41)$ \\
Living in Spain (years) & $2.13(3.03)$ \\
SELF-EVALUATED PROFICIENCY LEVELTEST IN L2 & \\
Production & $7.22(1.22)$ \\
Comprehension & $8.00(1.41)$ \\
Writing & $6.22(1.76)$ \\
Reading & $7.75(1.54)$ \\
\hline
\end{tabular}

The scores are on a 10-point scale, in which 10 represents native speakers level and one complete ignorance of the language. Mean are shown, with SD in parentheses.
Table A2 | Stimulus material.

\section{Incongruent (Spanish-Italian)}

\section{Congruent (Spanish-Italian)}

\section{EXPERIMENTAL PICTURES}

Almohada-Cuscino (pillow)

Cama-Letto (bed)

Mesa-Tavolo (table)

Mochila-Zaino (backpack)

Tapadera-Coperchio (lid)

Seta-Fungo (mushroom)

Tirita-Cerotto (band-aid)

Gaviota-Gabbiano (seagull)

Bota-Stivale (boot)

Mantequilla-Burro (butter)

Nariz-Naso (nose)

Flor-Fiore (flower)

Cepillo-Spazzola (brush)

Columpio-Altalena (swing)

Mono-Scimmia (monkey)

Trineo-Slitta (sled)

Zapato-Scarpa (shoe)

Cigarro-Sigaretta (cigaret)

Globo-Mongolfiera (hot air)

Mosquito-Zanzara (mosquito)

Zorro-Volpe (fox)

Tornillo-Vite (screw)

Coche-Macchina (car)

Enchufe-Spina (plug)

\section{CONTROL PICTURES}

Tenedor-Forchetta (fork)

Sobre-Busta (envelope)

Despertador-Sveglia (alarm clock)

Rallador-Grattugia (grater)

Hombro-Spalla (shoulder)

Látigo-Frusta (whip)

Araña-Ragno (spider)

Ardilla-Scoiattolo (squirrel)

Cartera-Portafoglio (wallet)

Galleta-Biscotto (cookie)

Escopeta-Fucile (shotgun)

Bata-Camice (white coat)
Bufanda-Sciarpa (scarf)

Falda-Gonna (skirt)

Mariposa-Farfalla (butterfly)

Maleta-Valigia (suitcase)

Ventana-Finestra (window)

Manzana-Mela (apple)

Calabaza-Zucca (pumpkin)

Iglesia-Chiesa (church)

Golondrina-Rondine (swallow)

Abeja-Ape (bee)

Sartén-Padella (pan)

Nuez-Noce (walnut)

Grifo-Rubinetto (faucet)

Loro-Pappagallo (parrot)

Taladro-Trapano (power drill)

Apio-Sedano (celery)

Cazo-Mestolo (ladle)

Corcho-Tappo (cork)

Sombrero-Cappello (hat)

Queso-Formaggio (cheese)

Perro-Cane (dog)

Vaso-Bicchiere (glass)

Tomate-Pomodoro (tomato)

Reloj-Orologio (clock)

Buitre-Avvoltoio (vulture)

Avestruz-Struzzo (ostrich)

Tiburón-Squalo (shark)

Paraguas-Ombrello (umbrella)

Gusano-Verme (warm)

Taburete-Sgabello (stool)

Zanahoria-Carota (carrot)

Jarra-Brocca (pitcher)

Olla-Pentola (pot)

Pata-Zampa (leg)

Carretera-Strada (road)

Cereza-Ciliegia (cherry) 